\title{
Overview on Islanding Detection Technology of Microgrid
}

\author{
Yaning Yuan \\ State Grid Jibei Electric Power Co. Ltd. Skill Training \\ Center \\ Baoding, China \\ E-mail: yuanyaning1990@126.com
}

\author{
Sen Yang \\ Shenyang Institute of Engineering \\ Shenyang, China \\ E-mail: yzlbddx@163.com
}

\begin{abstract}
The islanding detection is an essential function for microgrid, which requires quick and accurate island effect detection, at the same time with minimum impact on power quality. The significance, standard and methods of the microgrid islanding detection technology are discussed in the paper. The islanding detection methods commonly can be divided into two types, the remote method and the local method. The local method is divided into local passive method and local active method. The advantages and disadvantages of different islanding detection methods are analyzed and compared, and the development direction and trend of the detection technology is the composite islanding detection method, combined kinds of islanding detections.
\end{abstract}

Keywords- Microgrid; Islanding Detection; Remote Islanding Detection; Active Islanding Detection; Passive Islanding Detection

\section{INTRODUCTION}

In order to solve the energy shortage and environmental pollution problems, distributed clean energy power generation will become a new mode of energy use. Compared with the traditional centralized energy, it has the advantages of low investment, flexible generating method, high energy efficiency, and environmental protection [1]. At the same time, it has the notable features of stochastic volatility and intermittence, and the safe and stable operation of traditional power system will be impacted and affected due to the large scale access to the grid [2-3]. In order to give full play to the benefits and value of distributed generation, and weaken the negative impacts on power network, R. H. Lasseter of A merican W isconsin University proposed the concept of microgrid [4-5]. As a part of the large power system, the microgrid is a small power grid, which contains some DG devices.

When the interruption of power supply on the grid side happened due to the electrical equipment malfunction, misoperation or natural factors, and the distributed generation system failed to detect the outage state and the microgrid is not disconnected with the grid, the DG and the surrounding load form an independent power system, which is called the is land[6-7].

After the island happened, a series of hazards will come one after another. The voltage and frequency will be not stable in the area of the isolated island system which out of control of the main power network. When the main power grid is disconnected, the DG will be a threat to the line maintenance worker's personal safety. And the working procedure of overload protection devices in power distribution system will be affected.

In view of the above reasons, in the actual operation, islanding detection devices must be installed for distributed power generation equipments. Then the running state of the island can be detected quickly and accurately, which is helpful for taking corresponding measures to eliminate the harm islanding operation may bring.

\section{ISLANDING OPERATION}

\section{A. Intentional Islanding and Non-intentional Islanding}

Of course, microgrid includes two kinds of operating modes: grid connected operation and is land running mode. In grid connected operation, microgrid has characteristics of distribution network. Namely the distribution network provides support to it, and guarantees the voltage and frequency within the allowable range. The microgrid can absorb or generate power with the distribution network according to the situation of power matching. In the islanding mode, namely disconnected with the distribution network, the microgrid needs operating under the stable voltage and frequency, which requests the DGs to cooperate with each other using different control methods, to maintain the microgrid operating at rated voltage and frequency, and to ensure the power balance and power quality of the microgrid.

Is landing detection is a prerequisite for the transition from grid connected operation to isolated island operation. It is worth noting that there are differences between the isolated island operation and the island, and the island is not necessarily evolved into isolated is land operation. The isolated island operation is also called islanding effect. That is defined as a part of the distribution network, which is separated from the main system, and it operates by one or more DG independent power supply with a certain voltage and frequency.

According to the plan, the is land can be divided into intentional islanding operation and non- intentional is landing operation.

Before the power system fault, set up a reasonable is landing area which will be disconnected from the main system, according to the capacity of distributed generation and the size of the local load. And after fault, the small 
system can running smoothly, called intentional islanding operation.

Intentional islanding operation can effectively play the DG positive role, make full use of DG power ability, and improve the reliability of power supply. Through reasonable planning, division and effective control, the DGs can continue to supply the load around after disconnecting, also eliminating the adverse effect on the security and stability of power system. So the Intentional islanding operation makes the power system operation more efficient and reliable.

The formation of the non- intentional islanding is contingent and uncertain. It will create a series of problems to the safe and stable operation of power system, such as the security threat for the maintenance, operation personnel and public, poor electrical energy quality caused by the not timely adjustment or DG capacity limit, the damage for electrical equipment, and so on.

\section{B. Anti-islanding and Utilization of Islanding Operation}

The operation of the unintentional islanding can cause great harm to the power system. Based on this point, two viewpoints, anti-is landing and utilization of isolated is land operation, are put forward for it.

Anti-islanding is prohibition the occurrence of the operation of the non- intentional islanding. In the initial standard of IEEE Std.999-2000, as well as UL1741, distributed power generation devices must be equipped protection scheme, in order to prevent the occurrence of non-intentional islanding. According to this standard, in any fault conditions, all DG units must break off from the feeder line which has fault point. For some reason, if any DG failed to break off, then forming the island, at the same time, the islanding detection device detects the condition of islanding and makes the DG breaking off. And the obvious drawback is that the power supply is not reliable. And this method cannot make full use of DG's power generation capacity. This not only damages the interests of DG operators and users, but also contrary to the original intention of improving the reliability of power supply by using DG.

Another view is that the utilization of isolated island operation, that is, at the state of island, DGs continue to run. In order to maximize the use of DG generation capacity and improve reliability of power supply, a new international standard of IEEE Std.1547-2003 is proposed by IEEE. According to this standard, non- intentional islanding was not prohibited. The standard stressed that the using of islanding operation, and encourage users and providers of supply to achieve the islanding operation through the technical means. DG can continue to provide power supply to the load in the area of the isolated island operation, which significantly reduces the range of power outage, and improves the reliability of power supply. In order to realize the use of isolated island operation, we must develop the technology of islanding detection and islanding operation control.

\section{ST ANDARD OF ISLAND DETECTION}

The establishment of the islanding detection standards began in the early and mid 90's, and has been revised. Countries, in view of their own DG development characteristics different from other countries, make the testing standards also different from abroad. At first, many countries have developed the islanding detection standards which are specified using one or a few detection methods.

Give some examples. Japan requires at least a passive detection method and a kind of active detection. Dutch requires using the most basic method of over / under frequency passive detection method. Germany requires using center detection unit, and the detection unit consists of active method of impedance measurement and passive detection method of high / low frequency or over/ under voltage.

Along with the further development of DG technologies, currently the dominant standard is North American Standard. The standard mainly lies in the performance of is landing detection and testing process, not just limited to a specific detection method. In the isolated is land detection standards issued by China in 2005, one of the active and one of the passive detection methods are required at least, and the action time is also limited in $2 \mathrm{~S}$ after the power network loss voltage.

The islanding detection standards are not unified, which brings a lot of inconvenience to all DG manufacturers of various countries. Table $I$ is the maximu $\mathrm{m}$ limiting time of the is landing detection specified by IEEE[8].

T ABLE I. THE STANDARDS OF MAXIMUMDETETION LIMITING TIME BY IEEE ST D.929-2000/UL174

\begin{tabular}{|c|c|c|c|}
\hline State & $\begin{array}{l}\text { Voltage amplitude } \\
\text { after power off }\end{array}$ & $\begin{array}{l}\text { Voltage frequency } \\
\text { after power off }\end{array}$ & $\begin{array}{c}\text { Limiting } \\
\text { time }\end{array}$ \\
\hline A & $0.5 \mathrm{~V}_{\mathrm{N}}$ & $f_{N}$ & 6 cycles \\
\hline B & $0.5 \mathrm{~V}_{\mathrm{N}}<\mathrm{V}<0.88 \mathrm{~V}_{\mathrm{N}}$ & $\mathrm{f}_{\mathrm{N}}$ & $2 \mathrm{~s}$ \\
\hline $\mathrm{C}$ & $0.88 \mathrm{~V}_{\mathrm{N}} \leqslant \mathrm{V} \leqslant 1.10 \mathrm{~V}_{\mathrm{N}}$ & $\mathrm{f}_{\mathrm{N}}$ & $\begin{array}{c}\text { normal } \\
\text { operation }\end{array}$ \\
\hline $\mathrm{D}$ & $1.10 \mathrm{~V}_{\mathrm{N}} \leqslant \mathrm{V}<1.37 \mathrm{~V}_{\mathrm{N}}$ & $\mathrm{f}_{\mathrm{N}}$ & $2 \mathrm{~s}$ \\
\hline $\mathrm{E}$ & $1.37 \mathrm{~V}_{\mathrm{N}}<\mathrm{V}$ & $\mathrm{f}_{\mathrm{N}}$ & 2 cycles \\
\hline $\mathrm{F}$ & $\mathrm{V}_{\mathrm{N}}$ & $\mathrm{f}<\mathrm{f}_{\mathrm{N}^{-}}-0.7 \mathrm{H}_{\mathrm{Z}}$ & 6 cycles \\
\hline G & $\mathrm{V}_{\mathrm{N}}$ & $\mathrm{f}<\mathrm{f}_{\mathrm{N}}+0.5 \mathrm{H}_{\mathrm{Z}}$ & 6 cycles \\
\hline
\end{tabular}
$50 \mathrm{~Hz}$ in China.

\section{COMPARISON OF THE ISLANDING DETECTION METHODS}

\section{A. Basic Principle of Islanding Detection}

As shown in Fig. 1, when the inverter power supply is connected to the grid, the grid is connected with the inverter power supply at the point of common connection (PCC).

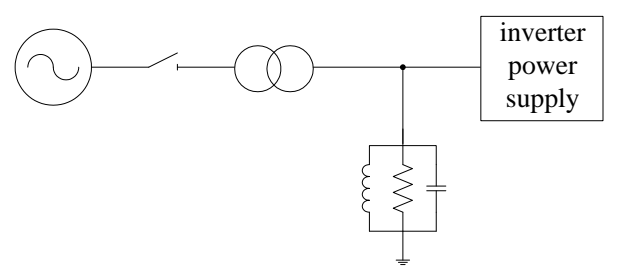

Figure 1. Schematic diagram of DG and system 
There are the following equations at PCC:

$$
\begin{gathered}
P_{\text {load }}=P+\Delta P \\
Q_{\text {load }}=Q+\Delta Q \\
P_{\text {load }}=V_{p c c}^{2} / R \\
Q_{\text {load }}=V_{p c c}^{2}(1 / \omega L-\omega C)
\end{gathered}
$$

Where, $\mathrm{V}_{\mathrm{pcc}}$ is voltage of the point of common connection. $\mathrm{P}, \mathrm{Q}$ respectively refers to the active output power and reactive output power of the inverter. $\mathrm{P}_{\text {load }}, \mathrm{Q}_{\text {load }}$ respectively refers to the active power and reactive power consumed by the load. $\Delta \mathrm{P}, \Delta \mathrm{Q}$ respectively refers to the active power and reactive power provided by the power grid. The above three equations can be simultaneous:

$$
\omega=\frac{1}{2 \sqrt{L C}}\left(\sqrt{\frac{Q_{\text {load }}}{P_{\text {load }} Q_{f}}+4}-\frac{Q_{\text {load }}}{P_{\text {load }} Q_{f}}\right)
$$

Where, $\mathrm{Q}_{\mathrm{f}}$ refers to the quality factor for load.

When non- intentional islanding occurs, main system no longer transports energy to the island, but the inverter output power can not immediately change. Therefore, at the moment of forming the island, there will generally produce power vacancy inside the island, namely $\Delta \mathrm{P} \neq 0$, $\Delta \mathrm{Q} \neq 0$, which resulting in $\mathrm{PCC}$ voltage and frequency changing accordingly. According to the Formula 3, when the active power is changed, it will trigger the following changes in voltage:

$$
\begin{aligned}
& \mathrm{P}>\mathrm{P}_{\text {load }} \rightarrow \mathrm{P}_{\text {load }} \uparrow \rightarrow \mathrm{V}_{\text {pcc }} \uparrow \\
& \mathrm{P}<P_{\text {load }} \rightarrow P_{\text {load }} \downarrow \rightarrow V_{\text {pcc }} \downarrow
\end{aligned}
$$

See from Formu la 5, the change of frequency is related with the active and reactive power, so it can be divided into three cases. First, reactive power unchanged and active power change. When the active power changes, it will make the PCC point voltage change. According to the Formula 5, due to reactive power unchanged, which leads to the change of frequency:

$$
\begin{aligned}
& \mathrm{P}>P_{\text {load }} \rightarrow P_{\text {load }} \uparrow \rightarrow V_{\text {pcc }} \uparrow \rightarrow \omega \uparrow \\
& \mathrm{P}<P_{\text {load }} \rightarrow P_{\text {load }} \downarrow \rightarrow V_{\text {pcc }} \downarrow \rightarrow \omega \downarrow
\end{aligned}
$$

Second, the case of active power unchanged and reactive power changes. The active power is constant, so the voltage constant. Then according to the Formula 5, the reactive power has changes.

$$
\begin{aligned}
& Q>Q_{\text {load }} \rightarrow Q_{\text {load }} \uparrow \rightarrow \omega \downarrow \\
& Q<Q_{\text {load }} \rightarrow Q_{\text {load }} \downarrow \rightarrow \omega \uparrow
\end{aligned}
$$

The third cases, the active and reactive power both have changes. It will be decided by the amplitude of variation of the active and reactive power.

When the gap between the power of the load and the power of the power source is large enough, it can cause the voltage and frequency exceeding the limit, and then detect the is land.

\section{B. Comparison of Islanding Detection Methods}

After many years development, the methods of islanding detection is approximately shown in Fig. 2.

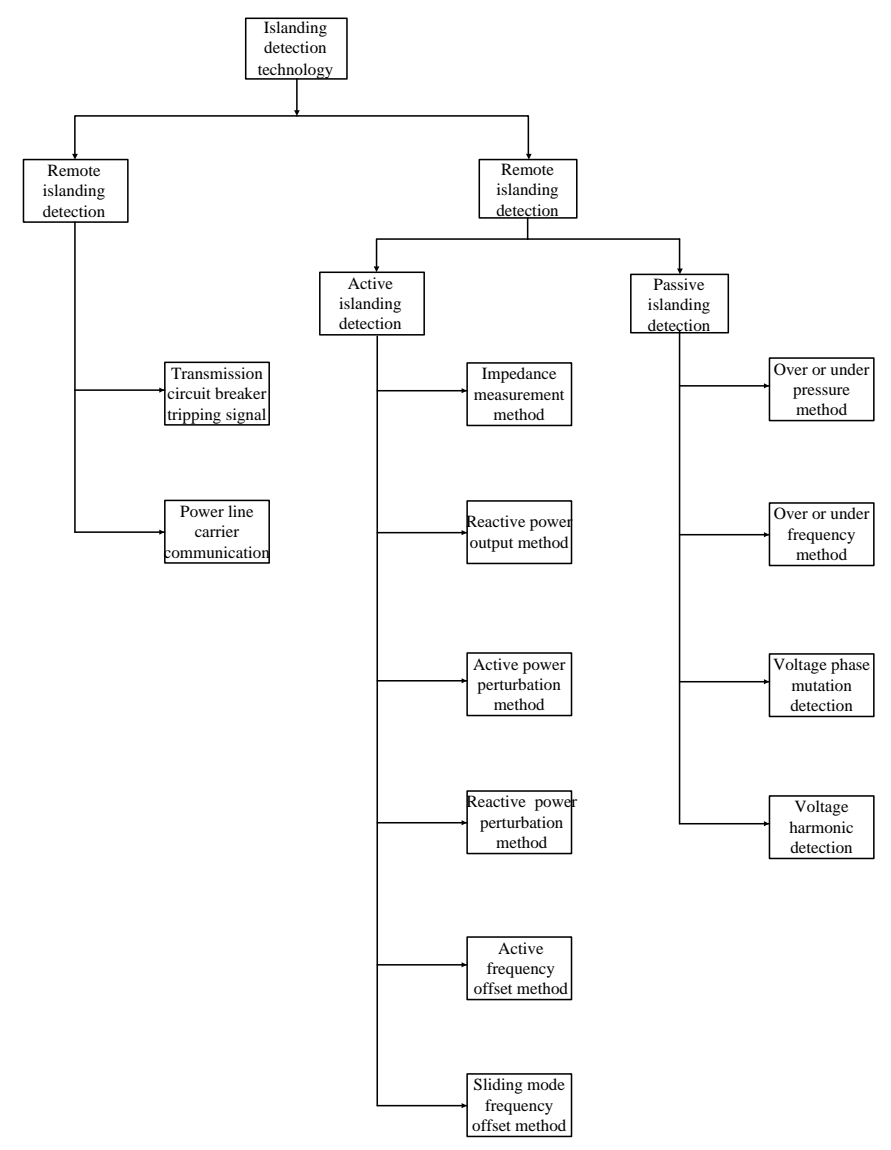

Figure 2. Classification of islanding detection method

According to the installation position of the detection device, either in the grid or in the inverter side, the is landing detection methods commonly can be divided into two types, the remote method and the local method. Besides, the local method is divided into local passive method and local active method [9-12].

The grid side detection method (also known as remote or external detection) is mainly used wireless communication means to detect the breaking state of the circuit breaker, and sends out carrier signal at the grid side. The receiver installed at DG side will determine whether the isolated island happened according to the change of these signals. When the power off, the signals of island state are sent to the grid-connected inverter, and make it cut off from the power supply. The remote method can be divided into the traditional circuit breaker tripping signal method and power line carrier communication method, etc. As the requisite equipment and investment are relatively large, the performance price ratio is not high, in the is land detection method based on the communication. Therefore, the proposed method mainly focuses on the local detection method.

The local passive method judges the isolated island phenomenon by the detection of the voltage amplitude, frequency, phase and harmonics of the output of the inverter when power off. It can be divided into voltage / 
frequency detection, voltage harmonic detection method and voltage phase mutation detection method, etc.

The local active method is respectively applied small disturbance signals to the inverter output voltage, frequency, and power [13]. Because of the grid balancing clamp, these disturbance signals have no obvious effect in grid connected operation, but the disturbance signals have obvious effect when island phenomenon happens. Then we can determine whether there is the phenomenon of island by detecting the PCC system response. It can be divided into impedance measurement method, voltage offset method, power perturbation method, active frequency drift method and sliding mode frequency drift method, etc.

The remote communication method achieves the control objectives by installing the generator directly, which can significantly reduce the blind area and increase the power supply reliability. The detection has good realtime performance and stability, and has no effect on power quality. But it needs multiple generating devices, which will result high cost, complicated operation and low economic profits.

The most common is landing detection method is the local detection method on the grid connected inverter side. It can be divided into passive detection and active detection method, the active islanding detection method is developed based on passive islanding detection method. Through detecting the frequency, voltage and the voltage harmonics phase, the passive detection method can judge whether islanding occurs. This method is simple and convenient, and has no effect on the electric energy quality. But when the output power of distributed generation system is equal to the power of user load, it is difficult to detect the islanding. So the non-detection zone is large, and sometimes gets wrong judgment. This method can only be used for general protection, and it applies to the condition of non large fluctuation of load power and having larger differences between power supply and the load. Active detection method joins a kind of disturbance in grid connected inverter actively. Generally, when the microgrid works at grid connected operation mode, the power is balance in the system. Then the disturbance cannot change the working state. The voltage, frequency or power changes due to the disturbance, when the distributed generation system breaks off fro $m$ the grid. So it can judge the occurrence of islanding.

The active detection has higher accuracy and precision, smaller non-detection zone or even no non-detection zone than the passive detection, but the joined disturbance will affect the power quality, and the control is more complicated and difficult to grasp accurately.

\section{CONCLUSION AND PROSPECT}

Both the passive detection method and the active detection method have their own advantages and disadvantages, and only using one of them cannot achieve a better detection result. Therefore, in recent years, people began to study the mixed type of islanding detection method, which is commonly based on the combination of a passive detection method and an active detection method. Such as the combination of voltage phase shift and improved active current disturbing, the combination of voltage average rate and active power migration, and the combination of phase mutation method and the improved active power disturbance method.

The composite islanding detection method, combined of two or more kinds of islanding detections, overcomes the insufficient of adopting only one detection method. It can not only improve the accuracy and sensitivity of islanding detection method, but also play a role in the prevention of false islanding protection. This idea will be one of the development mainstreams about the island detection technology in the future.

\section{REFERENCES}

[1] J. Yang, A. Qian, X. Da, "Research on co-developmental trend of distributed generation and smart grid," Power System Technology, vol. 34, 2010, pp. 15-23.

[2] L. Zongxiang, W. Caixia, M. Yong, "Over view on microgrid research," Automation of Electric Power System, vol. 31, 2007, pp. 100-107.

[3] W. Chengshan, W. Shouxiang, "Study on some key problems related to distributed generation systems," Aut omation of Electric Power System, vol. 32, 2008, pp. 1-4.

[4] R.H. Lasseter, " Microgrids: distributed power generation," Proc. IEEE Symp. Power Engineering Society Winter Meeting, IEEE Press, Columbus, OH, USA, 2001.

[5] C. Marnay, F.J. Robio, and A.S. Siddiqui, "Shape of the microgrid," Proc. IEEE Symp. Power Engineering Society Winter Meeting, IEEE Press, Columbus, OH, USA, 2001.

[6] L. Mingyao, G. Juan, S. Zhujie, "A Practical Hybrid Is-landing Detection Method for Grid-connected Photovoltaic System," Automation of Electric Power Systems, vol. 33, 2009, pp. 85-89.

[7] L. Fangrui, D. ShanXU, K. Yong, "Islanding Detection Methods for Multiple PV cOnverters System," Transactions of China Electrotechnical Society, vol. 25, 2010,pp. 167-171.

[8] IEEE Std.929-2000, IEEE Recommended Practice for Utility Interface of Photovoltaic(PV) Systems, Institute of Electrical and Electronics Engineers, Inc, NewYork, USA, 2000.

[9] H. Meimei, L. Huaqiang, G. Liyong, "Islanding Detection Scheme Evaluation for RLC Load Distributed Generation," Power System Protection and Control, vol. 39, 2011, pp. 7-11.

[10] D. Velasco, C.L. Trujillo, G. Garcera, "Review of anti. islanding techniques in distributed generators," Renewable and Sustainable Energy Reviews, vol. 14, 2010, pp. 1608-1614.

[11] H.H. Zeineldin, J.L. Kirt ley, "Islanding operation of inverter based distributed generation with static load models," IEEE Transactions on Power Systems, 2008, pp. 1-6.

[12] Y. Tao, W. Lujun, Z. Chong, "A Novel Islan-ding Detection Method Based on Positive Feedback Between Reactive Current and Frequency," Automation of Electric Power Systems, vol. 36, 2012, pp. 193-199.

[13] Y. Qiuxia, Z. Qinglin, G. Xiaoqiang, "Modeling and Analysis of Current-disturbance Based Islanding Detection for Three-phase Photovoltaic Grid-connected Invertem," Automation of El ectric Power Systems, vol. 36, 2012, pp. 45-49. 